\title{
Opioids: Government intervention and black markets
}

\author{
Gilbert G. Berdine MD
}

\begin{abstract}
The U.S. is in the midst of an opioid crisis. This crisis is partially responsible for declining life expectancy. The rising mortality in young people 25-44 is partially responsible and is being attributed to opioids. In this article, the formation of black markets in response to government regulation will be examined. We will also examine how the black market changes in character with subsidies. The subsidies available for Medicaid patients can be close to $100 \%$. The subsidy makes it profitable for Medicaid patients to be recruited as a source of supply of opioids. The economics of opioids and their black markets will be explained on the basis of supply and demand. The conclusion is that the type of illicit behavior occurring in the U.S. was both rational and predictable based on the regulation of narcotics, monopoly pricing of certain opioids, and the availability of government subsidies to obtain these opioids.
\end{abstract}

Keywords: opioid crisis, black market, free market, Medicaid subsidy

\section{BACKGROUND}

Life expectancy has decreased in the U.S. for two years in a row from 78.9 in 2014 to 78.7 in 2015 to 78.6 in 2016 according to data from the Centers for Disease Control (CDC). ${ }^{1}$ A significant contributing factor to this trend is a steady increase in mortality rate for young people age 25-44 from 139.8 deaths per 100,000 population in 2010 to 151.3 in $2015 .^{2}$ Opioids are being blamed. The National Institutes of Health (NIH) claims that more than 115 Americans die from opioid overdose every day. ${ }^{3}$ A recent report from the U.S. Senate claims that Medicaid subsidies are responsible. ${ }^{4}$ The Mises Institute presented a good overview of the history of the opioid crisis. ${ }^{5}$ This article will discuss the economics of black markets in general and explain how public financing increases the abuse of opioids.

Corresponding author: Gilbert G. Berdine Contact Information: Gilbert.berdine@ttuhsc.edu DOI: $10.12746 /$ swrccc.v6i23.460

\section{General Principles of Supply and Demand}

The 'free' in free market does not refer to a price. It refers to freedom of human action. The human actors in an economy are free to make choices unhampered by coercion. In any market, different actors have different values for the same things. These different valuations are the basis for mutually beneficial trade.

Figure 1 illustrates a free market. The $x$-axis is the quantity of transactions for a good or service. The $y$-axis is the price of transactions between sellers (suppliers) and buyers (demanders). The supply curve (blue) indicates the number of sellers willing to sell at each price. All supply curves demonstrate a slope greater than or equal to zero at every point. As price increases, more supply is offered for sale. The demand curve (red) indicates the number of buyers willing to buy at each price. All demand curves demonstrate a slope less than or equal to zero at every point. As price increases, there is a lower quantity demanded for purchase. Due to the positive slope of the supply curve, and the negative slope of the demand curve, the two curves intersect at one point. 


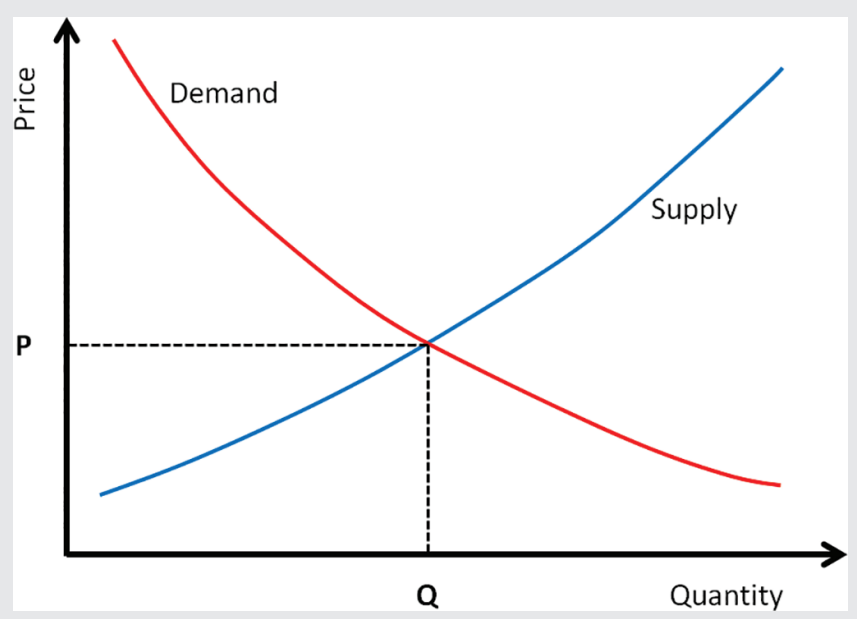

Figure 1. Supply, demand and market clearing price in an unhampered or free market.

This is called the market clearing point. This defines the quantity of transactions that will voluntarily be made between buyers and sellers and the market clearing price.

There are important properties of the market clearing price. At this price, there are no unsatisfied buyers or sellers. This is not to say that every buyer makes a purchase or that every seller realizes a sale, but rather after the conclusion of transactions, all market actors are left with what they value most. Buyers who do not make a purchase value the market clearing price greater than the good or service being traded. Sellers who do not realize a sale value the good or service being traded greater than the market clearing price. Any other price above or below the market clearing price would result in unsatisfied buyers and sellers.

\section{EFFECTS OF REGULATION}

Health care in general and opioids in particular are not a free market. Health care is heavily regulated. Opioids can be legally prescribed only by licensed practitioners. This reduces the quantity of supply at each price. The graphical result is a shift of the supply curve to the left. The reduction in quantity is not necessarily the same for each price. The regulated or legal supply curve may have a steeper or flatter slope at any point than the free market supply curve. The exact shape of the regulated curve is important to the outcome, but the general principles are not changed by different shapes.

Figure 2 illustrates the effect of regulated supply. Note that the regulated supply curve (cyan) is shifted to the left. For each price, there is a lower quantity available than would be available in the free market. There are two inexorable effects of the shift in the supply curve. The new intersection with demand must be at a lower quantity (Q') and a higher price (P'). The lower quantity is the intent of the regulation. Ideally, the licensed practitioners will prescribe the opioids only to those who need them and are not at excessive risk for taking opioids. As we shall see below, the real world result has been far from ideal. The increased in price is unintended, but it is also unavoidable. The other effect of the regulation is that there are both unsatisfied buyers and sellers due to the increase in price above the market clearing price. In the simplest of terms, the number of transactions has decreased by $Q-Q$ '. Some of these $Q-Q$ ' fewer buyers are

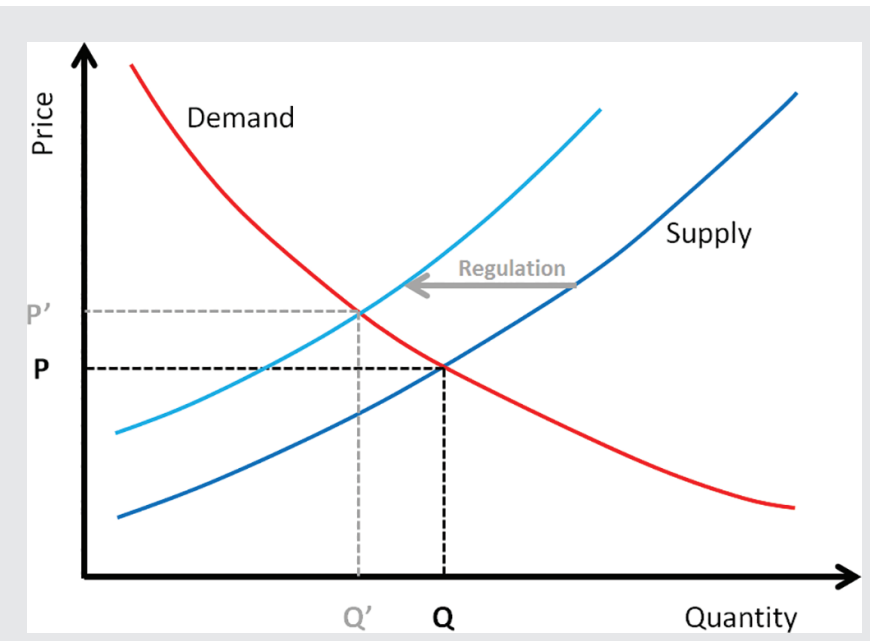

Figure 2. The effects of government regulation on the unhampered or free market. 
people who legally qualify for prescriptions, but who are unwilling to pay the higher price $\mathrm{P}^{\prime}$. All of the $Q-Q^{\prime}$ fewer sellers would be willing to sell at the higher price $\mathrm{P}^{\prime}$, but they are unable to find a legal buyer. Whenever both unsatisfied buyers and unsatisfied sellers exist simultaneously, there is an opportunity for arbitrage. In this case, the arbitrage is a black market of illegal sales. Being illegal, the transactions are necessarily made possible by criminals. Depending on how strict the regulation is enforced, the black market transactions will move the supply curve back toward the free market supply curve, increase the number of transactions back towards $Q$, and decrease the price back towards the market clearing price $P$.

The black market depends on a low cost supply. The $Q-Q$ ' fewer buyers cannot take advantage of people who are able to legally obtain prescriptions as any re-sellers would charge a price above P'. The criminals facilitating arbitrage look for low cost supply including the smuggling of drugs produced outside the jurisdiction of the authorities. Heroin and cocaine are examples. The criminals will also utilize alternative low cost drugs that can be illegally produced locally. Methamphetamine is an example.

There is another black market that will become more important when we discuss the effects of subsidies. Some of the people who purchased opioids prior to regulation cannot obtain legal prescriptions after the regulations. For these people, opioids are not available at any price. Some members of this group who have substantial means will be willing to pay a very high price (above P') for illegal supply. It would be possible for this group to buy opioids from patients who buy legal drugs with prescriptions. These people could also satisfy their demand from unscrupulous prescribers or pharmacists rather than recruiting patients to re-sell part of their legal price. The high price and absence of subsidy keeps this volume of illicit trade low.

\section{EFFECTS OF SUBSIDY}

Figure 3 illustrates the effect of subsidy. Medicare, Medicaid and private insurance all have subsidies for

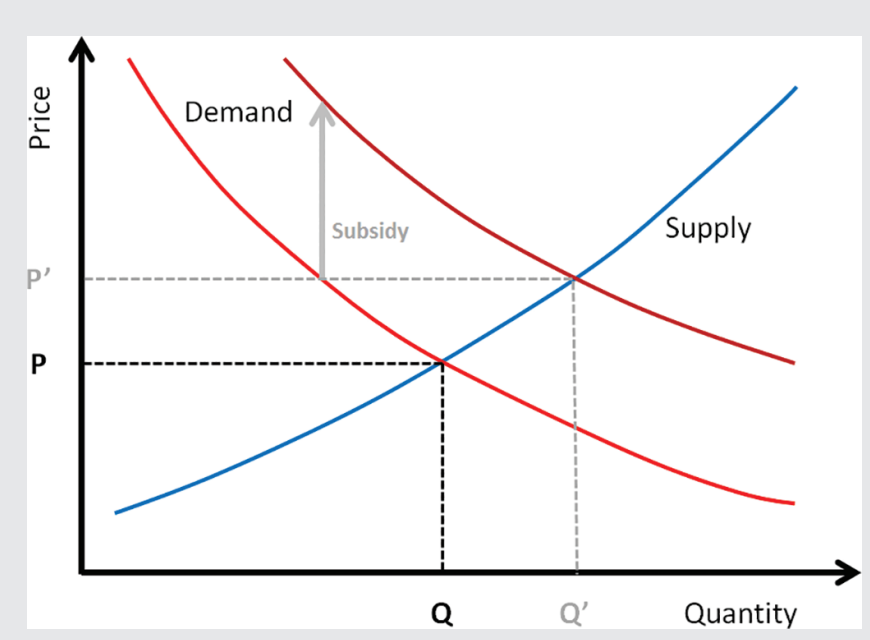

Figure 3. The effects of subsidy on the unhampered or free market.

prescription drugs. The subsidy makes the transaction price appear smaller to the buyer. The seller receives the full price, but the buyer pays only a fraction of the price and the difference is made up by the subsidy. For Medicaid, the subsidy is usually $100 \%$, so the Medicaid patient receives prescription drugs for free. The effect of the subsidy is to raise the price that buyers are willing to pay for any quantity of transactions. This shifts the demand curve up. Note that subsidized demand curve (dark red) intersects the supply curve at a higher quantity Q' and a higher price P'. The increase in number of transactions is the desired effect of the subsidy, while the higher price is an unintended, but unavoidable, side effect. It should be noted that economists usually visualize the demand curve shifting either left (decrease quantity) or right (increase quantity) rather than down (decrease in price) or up (increase in price). The results of a shift up or shift to the right are the same and both can be considered to be an increase in demand.

Not everyone qualifies for the subsidy. There are patients who want the drug, but who cannot afford the higher price P'. The subsidy creates an important new group of people: those who qualify for the subsidy but who do not want to consume the drug. For Medicaid, 
this subgroup can legally obtain the drug for free by pretending to "need" the drug, and they can then sell the drug to the unsatisfied buyers at a lower price than these unsatisfied buyers can legally obtain the drug. Both the Medicaid patient who re-sells and the unsubsidized patient profit from this black market exchange.

There still exist wealthy buyers who want to consume the opioid, but who cannot legally obtain a prescription. Rather than dealing with drug criminals, who can be violent, these people can use subsidized Medicaid or Medicare patients to obtain opioids. As noted by a recent Senate report ${ }^{4}$ on the opioid problem, the black market value for some prescription opioids can be as high as $\$ 4,000$ for a month supply. It does not require much imagination to recognize that poor people on Medicaid will be willing to pretend to have pain, legally obtain opioids to treat the pain, and then re-sell the opioids for a large profit. The profits are so large, that every possible scenario involving unscrupulous prescribers, unscrupulous pharmacists, and unscrupulous Medicaid or Medicare patients has been tried in real life. The following case summaries were taken from the Senate report on how Medicaid fueled the opioid epidemic. ${ }^{4}$ The case numbers are the ones used in the report.

Case 1: Drug ring near New Haven, Connecticut: Medicaid recipients were recruited to act as "runners" filling illicit prescriptions using Medicaid cards. Pharmacies did not question the phony prescriptions, because the beneficiaries had Medicaid.

Case 2: Bronx Drug Market: A back room in a Bronx grocery store was used to exchange opioids from Medicaid recipients in exchange for cash. The dealers would re-sell to pharmacies and individuals on the street.

Case 4: A \$1 Billion Fraud. The owner of a group of 30 skilled nursing facilities admitted patients who did not qualify for skilled nursing facility (SNF) care. Patients were enticed to stay in the facility by getting opioids. Once admitted, practitioners would deliver medically unnecessary care and procedures to the patients and bill Medicare and/or Medicaid.
Case 9: A physician in Ohio saw up to 100 patients per day charging $\$ 100$ per visit. Medicare, Medicaid and medical care organizations (MCO) were billed for histories and exams that were not performed. Patients received prescriptions for opioids. Many paid cash for the visits. The prosecutors claimed that the activity fueled drug trafficking and addiction in at least 7 states outside of Ohio, including Texas.

Case Summary 4: A New Mexico physician used a pain management practice to prescribe more than 3 million doses of pain medication to over 3,200 patients. He was the top prescriber of pain medications in the state of New Mexico. The second place prescriber was the entire resident physician staff using a single DEA number at the University of New Mexico resident training program.

Case Summary 76: A Texas physician and his office manager "allowed unlicensed staff to prescribe controlled substances, including Suboxone, to patients when he was not present and had not treated the patients." The drugs were distributed directly to patients rather than by pharmacies via prescription. False claims to Medicare and Medicaid totaled more than $\$ 300,000$.

\section{Conclusions}

There is no way to prevent these black markets from emerging. There are no objective measures of pain. It is not possible to distinguish every person who is fraudulently seeking opioids from the patients who are really experiencing pain and who require the opioids. It is even more difficult to determine how many opioid doses are really necessary in a patient who has objective findings of injury or illness. It is not possible to prevent patients with Sickle Cell disease from obtaining more pain medication than they truly need and selling the excess on the black market. The only effective way to stop the problem would be to end the War on Drugs, end monopoly profits for opioid manufacturers, and stop the subsidies made necessary by these monopoly profits. 
Article citation: Berdine G. Opioids: government intervention and black markets. The Southwest Respiratory and Critical Care Chronicles 2018;6(23):28-32

From: Texas Tech University Health Sciences Center, Lubbock, Texas; Free Market Institute, Lubbock, Texas

Submitted: $3 / 6 / 2018$

Accepted: 4/3/2018

Reviewer: Robert P Murphy PhD

Conflicts of interest: none

This work is licensed under a Creative Commons

Attribution-ShareAlike 4.0 International License.

\section{REFERENCES}

1. Tinker B. US life expectancy drops for second year in a row. 2017, at https://www.cnn.com/2017/12/21/health/us-lifeexpectancy-study/index.html

2. Achenbach J, Keating D. Drug crisis is pushing up death rates for almost all groups of Americans. 2017, at https://www. washingtonpost.com/national/health-science/the-drug-crisis-isnow-pushing-up-death-rates-for-almost-all-groups-of-americans/ 2017/06/09/971d8424-4aa1-11e7-a186-60c031eab644_story. html?utm_term=.fa0a51f3ceae

3. Opioid Overdose Crisis. 2017, at https://www.drugabuse. gov/drugs-abuse/opioids/opioid-overdose-crisis

4. Johnson R. "Drugs for Dollars How Medicaid Helps Fuel the Opioid Epidemic" A Majority Staff Report of the Committee on Homeland Security and Governmental Affairs United States Senate. 2018

5. GoffT. How to Kill 300,000 Americans with Opioids. 2018 at https://mises.org/wire/how-kill-300000-americans-opioids 